\title{
Understanding barriers to BIM implementation: Their impact across organizational levels in relation to BIM maturity
}

\author{
(C) The Author(s) 2020. This article is published with open access at link.springer.com and journal.hep.com.cn
}

\begin{abstract}
This multiple case study of a contracting firm contributes to understanding the barriers that organizations face during the implementation of building information modeling (BIM) by providing insights into the impact of these barriers across different organizational levels (i.e., from top management to project teams) and by relating these barriers to different degrees of BIM maturity. First, we observe the dominance of barriers related to the motivation, competence, and time capacity of people across all levels of an organization. Second, the cluster of barriers at the middle-management level highlights the important role of this level in reducing these barriers. Third, only those cases with a low level of BIM maturity have struggled with lack of top management support, thereby highlighting the importance of such support in achieving BIM maturity growth. High BIM maturity situations are more prone to externally oriented barriers in attempting to further leverage the benefits of BIM. Our study provides insights on where to focus BIM implementation measures and how to enhance organizational BIM maturity.
\end{abstract}

Keywords building information modeling, implementation barriers, maturity, organizational levels

\section{Introduction}

Recognized as one of the least digitalized economic sectors (Barbosa et al., 2017), the construction industry is slowly

Received August 29, 2019; accepted November 15, 2019

Sander SIEBELINK (凹), Hans VOORDIJK, Arjen ADRIAANSE

Department of Civil Engineering, Faculty of Engineering Technology, University of Twente, Enschede, The Netherlands

E-mail: s.siebelink@utwente.nl

\section{Maaike ENDEDIJK}

Department of Educational Sciences, Faculty of Behavioural, Management and Social Sciences, University of Twente, Enschede, The Netherlands catching up over the past decade by adopting building information modeling (BIM), which is expected to significantly increase its productivity and reduce its costs (McGraw Hill Construction, 2014; Gerbert et al., 2016). Several maturity models have been developed to gain insights into an organization's progress in adopting BIM. Accordingly, these models can be used to evaluate the BIM maturity of organizations on the basis of various technological and organizational criteria (Bew et al., 2008; Messner and Kreider, 2013; National Institute of Building Sciences, 2015; Siebelink et al., 2018; Succar, 2009). However, to support organizations in their BIM development, one must go beyond merely assessing their BIM maturity. To further understand what is stopping organizations from maturing in terms of BIM use, the barriers that these organizations face in their efforts to implement BIM and increase their BIM maturity must be explored.

Previous studies have identified many barriers that prevent organizations in implementing BIM, such as their lack of motivation to change their BIM practices (Adriaanse et al., 2010b; Gu and London, 2010; Eastman et al., 2011; Chien et al., 2014), insufficient knowledge and competence in BIM (Adriaanse et al., 2010a; Arayici et al., 2011; Liu et al., 2015), insufficient technological means, lack of IT support, interoperability issues with different software, and limited data exchange (Chien et al., 2014; Li et al., 2009; Miettinen and Paavola, 2014).

Given that the construction industry is striving to improve its BIM maturity, we wonder whether such development is accompanied by a decrease or change in the barriers to this industry's BIM implementation. In other words, the types of barriers that an organization can face given a certain degree of BIM maturity remain unknown. Previous studies have focused on providing an overview of these barriers regardless of the influence of BIM maturity on their occurrence. However, these studies do not offer an in-depth understanding of how these barriers can manifest themselves across different levels of an organization (e.g., strategic and operational levels) and have failed to identify 
those actions that need to be taken to overcome these barriers. To address these gaps, this research aims to improve our understanding of the extent and types of barriers to BIM implementation and use in relation to the current BIM maturity of organizations. We will use organizational levels as a framework to classify the characteristic barriers and to provide insights into the impact of these barriers on the BIM implementation process from the strategic top management level down to the project operation level. In this way, we provide some valuable insights that managers can use to remove or influence these characteristic barriers.

To meet this objective, we perform a multiple case study in which we examine the BIM maturity level and implementation barriers in a large contracting firm that is participating in many complex and multidisciplinary projects, especially in the western European market. This contracting firm provided us access to cases with variations in BIM maturity and barriers. We collected our data by conducting interviews with the BIM department representatives of the organization, analyzing its BIM strategic documents, and participating in BIM steering group meetings.

Compared with previous studies, our case study provides a novel perspective on BIM implementation barriers in three ways. First, our adopted approach allowed us to map barriers on different organizational levels and subsequently identify the relationships among the implementation processes of strategic BIM initiatives across different levels of analysis. Second, the relationship of BIM maturity and barriers with BIM implementation and use allowed us to understand the occurrences and barriers that organizations typically face in their pursuit of increased maturity. Third, our interviews with BIM department managers and experts helped us further understand the BIM implementation strategy of their organization from their own perspective. In doing so, our work differs from previous research where respondents from different organizational levels (i.e., from strategic or operational levels) are not explicitly distinguished, thereby leaving room for multi-interpretable findings.

Our approach also allowed us to extend the current theoretical insights into the barriers to BIM implementation and use as elaborated below.

\section{Theoretical background}

The existing theories have contributed novel insights into many barriers that hinder the implementation and use of BIM. The barriers identified in the literature can be classified into (1) management support, (2) people and culture, (3) technology, and (4) use of defined processes and standards. We will formulate our main research questions on the basis of this literature review of barriers.

\subsection{Management support for boosting BIM initiatives}

The insufficient commitment or leadership of senior management in implementing BIM in their organizations has been identified as an important barrier to BIM implementation and cause of poor BIM performance (Won et al., 2013; Chien et al., 2014). In addition to lack of managerial support, traditional management approaches also seem not to fit well with BIM implementation, and nor does a traditional organizational structure with the associated distribution of tasks and responsibilities (Won et al., 2013; Chien et al., 2014).

Lack of management support is often manifested in insufficient financial resources as reflected in the high initial costs of the BIM implementation process (Liu et al., 2015). Beyond these short-term investments, the lack of long-term financial support is considered a significant barrier due to the lack of continuous investment to support BIM implementation (Won et al., 2013). At the operational level, the high costs of software and hardware have been identified as barriers (Chien et al., 2014) along with the costs associated with the education and training of personnel and with the setting up of modified BIM processes (Liu et al., 2015).

Another barrier to BIM implementation at the management and strategic level is the lack of evidence regarding the success or quantifiable benefits of BIM initiatives. Given that managers are looking to legitimize their allocation of resources to BIM implementation, the lack of evidence regarding the benefits of BIM for the project participants and the project phases limits the willingness of management to focus on BIM implementation ( $\mathrm{Li}$ et al., 2009; Lu et al., 2014; Miettinen and Paavola, 2014). Furthermore, when a clear focus on BIM is present and when the expectations are high, the real impact of BIM tends to be exaggerated, thereby leading to misconceptions and disappointment (Miettinen and Paavola, 2014).

\subsection{Willingness and competence of people to use BIM}

The second hindering factor identified in the literature can be summarized as the influence of people's motivation, knowledge, and skills and the organizational culture on the implementation and use of BIM. In general, the construction sector has an unsupportive organizational culture that hinders its implementation of BIM. Such an organizational culture is often characterized by the absence of goal setting and team orientation (Cheung et al., 2011). At the individual level, the lack of intrinsic motivation due to perceived complexity, perceived disadvantages, time pressure, and distrust toward technology significantly hinders the application of BIM and leads to the persistent use of traditional approaches (Adriaanse et al., 2010a; Gu and London, 2010; Eastman et al., 2011; Chien et al., 2014). 
In terms of external motivation, the lack of client requirements for using BIM has been identified as one of the main impediments (Eastman et al., 2011). In the absence of a clear mandate in the form of a contract or enforced (inter-)national standards, organizations feel that they do not need to implement BIM (Adriaanse et al., 2010a; Volk et al., 2014). Another external factor is the lack of motivation to adopt BIM in supply chain collaborations, which are often hampered by conflicting organizational interests and differing organizational backgrounds (Gal et al., 2008). As a result, supply chain partners are often unwilling to participate in the BIM proposal of the general contractor (Eastman et al., 2011). At the project level, the lack of willingness to share information with project participants has been identified as a barrier to BIM implementation (Won et al., 2013).

Many researchers have stressed the importance of knowledge and skills in implementing and using BIM. Generally, the lack of trained personnel prevents organizations from transitioning to BIM (Underwood and Isikdag, 2009; Eastman et al., 2011; Chien et al., 2014). Such limitation has been linked to insufficient skills and knowledge to work with new technologies or to use certain applications (Adriaanse et al., 2010a; Arayici et al., 2011; Liu et al., 2015). Insufficient training on BIM applications, which also applies to young and recently graduated employees, is considered an important cause of a limited skilled workforce ( $\mathrm{Gu}$ and London, 2010). However, simply increasing the amount of training is not very effective in practice because organizations are struggling to define who and to what extent should their people be skilled in using BIM (Underwood and Isikdag, 2009). Moreover, the incentives to invest in BIM training are limited given the lack of understanding regarding the added value of BIM or how such technology should be used to gain the most benefit ( $\mathrm{Li}$ et al., 2009; $\mathrm{Gu}$ and London, 2010; Arayici et al., 2011; Miettinen and Paavola, 2014). Organizations also have insufficient knowledge about how BIM can contribute to the daily work of their employees (Underwood and Isikdag, 2009). Previous studies have also negatively commented on the capabilities of supply chain partners. Specifically, project partners are incapable of adopting the intended project approach to BIM (Eastman et al., 2011). At times when these project partners intend to use BIM to collaborate with one another, their lack of BIM capabilities presents a risk to the reliability and credibility of BIM as their main source of information (Miettinen and Paavola, 2014).

\subsection{Technology to facilitate the digitization of processes}

Technological aspects are less prominent yet are still considered important barriers to the adoption of BIM. From a technological perspective, the limited interoperability of different software packages has been considered a barrier to BIM implementation and use mainly due to the dispersed landscape of BIM software, other related software, and tools ( $\mathrm{Li}$ et al., 2009; Gu and London, 2010; Miettinen and Paavola, 2014). The data to be exchanged may also be incompatible with other software packages when other parties or disciplines work with native data formats (Chien et al., 2014). The organizational IT infrastructure also lacks support for the implementation and use of BIM (Eastman et al., 2011), thereby leading to misalignment between technologies and working practices and restricting the use of technologies in the intended manner (Adriaanse et al., 2010a).

\subsection{Need to define processes and standards}

Another barrier to BIM implementation is related to the changes and institutionalization of procedures and aspects related to contracts, standards, and legislation. In terms of change, organizations often struggle with BIM implementation because of the absence of standardized work procedures for BIM or the ambiguity of these procedures (Adriaanse et al., 2010a; Won et al., 2013). Therefore, organizations struggle to transform and integrate new BIM practices into their traditional processes (Arayici et al., 2011; Chien et al., 2014).

From the legal and contractual perspective, organizations face problems in defining contracts in a BIM context, including the ownership of intellectual properties, protection of copyright, and dispute settlement mechanisms $(\mathrm{Gu}$ and London, 2010; Eastman et al., 2011; Chien et al., 2014; Miettinen and Paavola, 2014).

In terms of standards, previous studies show that the sectoral standards for information exchange are insufficient or not well defined (Grilo and Jardim-Goncalves, 2010; Eastman et al., 2011).

\subsection{Linking barriers to BIM maturity and organizational levels}

As shown above, organizations face a wide variety of barriers in their BIM implementation and use. However, previous studies have failed to provide guidance or appropriate measures for overcoming these barriers. To address these problems, we need to expand our knowledge about the situations in which we can expect certain barriers. Previous studies have already highlighted the varying BIM maturity levels of organizations (Siebelink et al., 2018). The barriers being faced by organizations with a strong focus on BIM and a well-structured BIM use are expected to differ from those being faced by organizations that have only recently started to implement BIM. Therefore, we investigate the barriers to BIM implementation in relation to the BIM maturity of organizations.

Moreover, even though we have identified that the barriers to BIM implementation can affect various organizational levels (from top management to the 
operational level) and the external environments of an organization, a comprehensive understanding of these barriers is lacking. To provide further insights into those organizational levels where certain interventions are most effective, we will analyze these barriers with respect to the organizational level where they appear. In so doing, we will generate actionable knowledge on how organizations can improve their BIM maturity.

In sum, our study aims to further understand the relationship between BIM implementation barriers and the BIM maturity of an organization with support from advanced insights into the organizational levels on which these barriers are observed. To this end, we define the following research questions:

Question 1: How can the barriers that an organization faces in its BIM implementation and use be mapped to the affected organizational levels?

Question 2: To what extent are these barriers related to organizational BIM maturity?

\section{Methodology}

This study aims to further understand the barriers to BIM implementation and use in organizational settings, especially the organizational levels on which these barriers are observed and how these barriers are related to BIM maturity. Achieving this aim requires insights into the complex interaction among the BIM implementation process, the initiatives undertaken across different organizational levels, and the occurring barriers. Following the arguments of Eisenhardt (1989) and Yin (2003), we adopted a multiple case study approach to understand the complex BIM implementation barriers in their specific and natural contexts. In contrast to other studies that involve large samples, our investigation of a relatively small number of cases provides a wealth of detail that we can leverage to extract cause-effect relationships from our theoretical constructs (Hall, 2006).

We conducted an in-depth multiple case study of BIM maturity and BIM implementation barriers in a large contracting firm with more than 20000 employees spread over nine distinct organizational units, which form our cases. These nine organizational units are operating in offices across different western European markets. Offices vary in terms of size and focus on either civil structures or buildings disciplines. Nevertheless, they all share the strong common strategic BIM intent of the firm to achieve a leading position in the construction industry. Given the defined BIM strategy, BIM departments within individual units have to set up and guide the BIM implementation process in their respective offices. A general contractor was selected because of its central position in projects, which allowed a broad view of experienced barriers, crossing different project phases and involved disciplines. As such, the selected firm was representative of a diversity of firms in the construction industry. Our particular contracting firm was selected in consideration of the aims of the research, which called for a large yet fragmented firm with sufficient potential to show diversity in its BIM maturity. Selecting such a firm enabled us to link our case study outcomes to the identified BIM maturity levels.

\section{Data collection and analysis}

We interviewed BIM department heads, BIM managers, technical BIM specialists, and information managers from various departments in face-to-face settings to assess the BIM maturity and gather insights into the BIM implementation barriers being faced by their organizations. The first author participated in meetings with managers and experts from the BIM departments and, by doing so, developed a good understanding of the organizational setting and context before conducting interviews. The interviewees possessed broad and comprehensive knowledge of the status of BIM in their organizations and could reflect critically on the barriers encountered during the implementation of BIM in their departments and projects. Each semi-structured interview lasted for 1.5 to $2 \mathrm{~h}$, which allowed us to ask key questions regarding the aspects of BIM maturity and implementation barriers and left some room for follow-up discussions on interesting or surprising topics that emerge during the interviews (Myers and Newman, 2007). The interviews were recorded and transcribed, and the results were shared with the interviewees before they were discussed in the steering group to verify whether both the interviewee and the other BIM representatives recognized the outcomes. Representatives from each case participated in steering group meetings, which aimed to share and align their BIM goals and initiatives. The interview outcomes were also used to steer the BIM policies in the organization.

The initial interview questions were related to the functions of the interviewees in their organizations and about how, from the perspective of their respective departments, they had organized BIM implementation. We extensively asked the interviewees about the barriers that their organizations were facing in their BIM implementation and use. Apart from asking information about the barriers, the interview questions also aimed to reveal the causes, consequences, and actions taken to address these barriers. The interviews also gathered information about those organizational levels that were mainly affected by these barriers. To define these organizational levels, we perceived BIM implementation as a change process that propagates throughout an organization (Whelan-Berry et al., 2003) and is affected by many different internal and external factors (Duncan, 1972). We integrated these definitions with appropriate levels into the context of the construction industry (Kamara et al., 2002) and the organizational structure within the studied units. In doing so, we identified a top 
management level, which was followed by a layer consisting of the IT and BIM departments and a project level consisting all operational project teams. We also specified an external environment consisting of factors related to clients, partners, and sectoral regulations.

The subsequent part of the interview was more structured than the former and involved a set of questions related to the 18 criteria for a BIM maturity model that was previously developed and validated in a sectoral analysis of the Dutch construction industry (Siebelink et al., 2018). Following this model and the corresponding method, we assessed aspects related to strategy, organizational and project structures, people and culture, BIM-related processes, IT infrastructure, and data structure. We asked several questions related to each of these criteria to verify whether all conditions for a particular maturity level were met. When these criteria are satisfied, the BIM maturity level of an organization can increase incrementally to the next level, thereby introducing a new set of questions. In doing so, the responses of the interviewees could be translated into a BIM maturity score for each criterion. The closing interview questions focused on those aspects that the interviewees either missed during the interview or wanted to elaborate upon. Figure 1 summarizes the main parts of the interview structure.

We improved the validity of our study by performing triangulation during our data collection and analysis (Scandura and Williams, 2000). Specifically, we studied BIM strategic documents and analyzed the field notes we collected from our BIM steering group meetings and interviews. The minutes and documents from these steering group meetings were also available. By using multiple data collection sources, we could check whether the interview data were consistent with the findings from

Interview part I

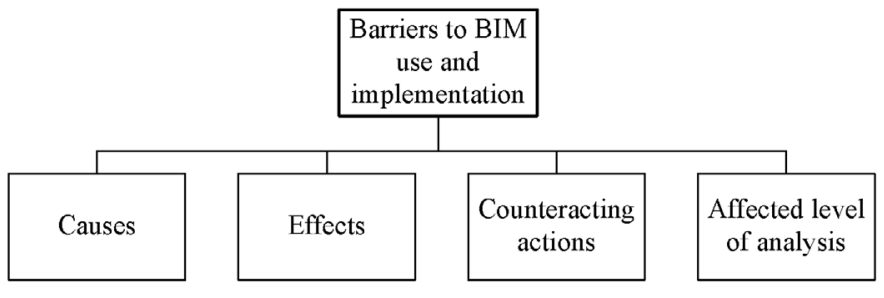

Interview part II

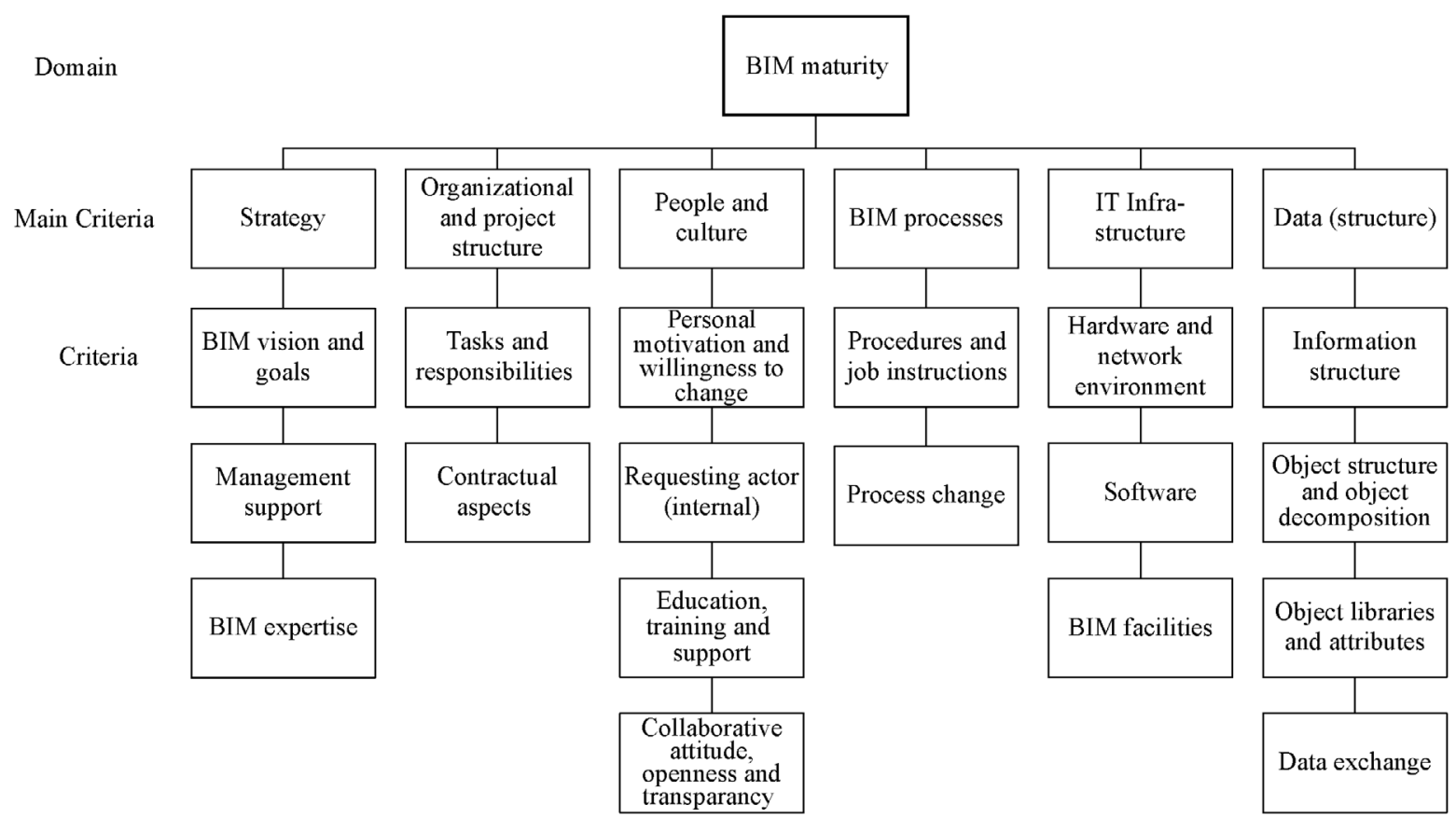

Fig. 1 Graphical representation of the interview structure, which covers the two main theoretical constructs. Part I includes questions on barriers to BIM implementation and use and their characteristics. Part II includes questions related to the 18 BIM maturity criteria (Siebelink et al., 2018). 
the documentation and meetings. We further improved the validity of our findings by performing a reflexive member check (Cho and Trent, 2006), which enabled all interviewees and other steering group members to reflect and comment on the study outcomes. Their reflections contributed to the final refinements made to this article. Table 1 presents an overview of the main case characteristics and data sources.

Our data analysis was divided into three main stages. The first stage analyzed the data on barriers to BIM implementation and use. The second stage positioned the identified barriers on the affected organizational levels. The third stage analyzed the data on BIM maturity, which enabled us to map the barriers to BIM implementation and use onto characteristic degrees of BIM maturity. These stages are described further in the following (see Fig. 2).

The data analysis in the first stage followed the approach of Gioia et al. (2013), who performed first- and secondorder analyses of their interview data. We started by creating first-order codes on the basis of interview quotes related to the barriers to the implementation and use of BIM. This stage aimed to identify the barriers in each case as described by the interviewees. We also identified several characteristics related to each of these barriers, their causes, their consequences, and-if mentioned by the interviewee - the actions taken to address them. Following the inductive approach of Gioia et al. (2013), we performed a second-order analysis of our data to generate themes for the first-order barriers. This stage involved interpreting the quotes from the interviewees to arrive at commonalities in meanings and opinions on a highly abstract level. The review of existing literature provided a useful reference for defining these second-order codes, but we did not limit ourselves to the existing theories. We then distilled these second-order themes into overarching categories to construct a framework that provided a clear understanding of the barriers. The created data structure facilitated the interpretations of data among the authors and the achievement of a consensus. We also consulted archival data to validate our understanding of the interview data.

In the second stage, we allotted the barrier themes and overarching dimensions to those organizational levels we identified from our interview data. This procedure resulted in a mapping from which we could distinguish whether individual barriers occur on one or more levels of the organization (e.g., only the top or middle management level).

In the third and final stage, the BIM maturity data were included in the analysis. Following the BIM maturity assessments we conducted as part of the interview analyses, we determined the BIM maturity level for each case. As shown in Fig. 1, this procedure involved 18 criteria related to both the technical and non-technical

Table 1 Data collection and case characteristics

\begin{tabular}{|c|c|c|c|}
\hline Cases & Interview data & Archival data & Observational data \\
\hline $\begin{array}{l}\text { Case } 1 \\
\text { Sector: Buildings and civil }\end{array}$ & $\begin{array}{c}2 \text { interviews: } \\
\text { - Head of BIM department } \\
\text { - Technical BIM specialist }\end{array}$ & $\begin{array}{l}\text { - Overarching organizational strategy } \\
\text { - Strategic plans of individual units } \\
\text { - Work package plans to structure and }\end{array}$ & $\begin{array}{l}\text { Two-day steering group meetings } \\
\text { attended (11 in total) }\end{array}$ \\
\hline $\begin{array}{l}\text { Case } 2 \\
\text { Sector: Buildings and civil }\end{array}$ & $\begin{array}{l}2 \text { interviews: } \\
\text { - BIM manager } \\
\text { - Lead BIM engineer }\end{array}$ & $\begin{array}{l}\text { guide specific BIM implementation } \\
\text { and use } \\
\text { - Steering group meeting minutes }\end{array}$ & \\
\hline $\begin{array}{l}\text { Case } 3 \\
\text { Sector: Buildings }\end{array}$ & $\begin{array}{l}2 \text { interviews: } \\
\text { - Head of BIM department } \\
\text { - BIM advisor }\end{array}$ & & \\
\hline $\begin{array}{l}\text { Case } 4 \\
\text { Sector: Buildings }\end{array}$ & $\begin{array}{l}1 \text { interview: } \\
\text { - Head of BIM department }\end{array}$ & & \\
\hline $\begin{array}{l}\text { Case } 5 \\
\text { Sector: Buildings and civil }\end{array}$ & $\begin{array}{c}2 \text { interviews: } \\
\text { - BIM manager } \\
\text { - BIM implementation manager }\end{array}$ & & \\
\hline $\begin{array}{l}\text { Case } 6 \\
\text { Sector: Civil }\end{array}$ & $\begin{array}{l}2 \text { interviews: } \\
\text { - Head of BIM department } \\
\text { - Digital systems manager }\end{array}$ & & \\
\hline $\begin{array}{l}\text { Case } 7 \\
\text { Sector: Buildings }\end{array}$ & $\begin{array}{l}2 \text { interviews: } \\
\text { - BIM manager } \\
\text { - BIM specialist }\end{array}$ & & \\
\hline $\begin{array}{l}\text { Case } 8 \\
\text { Sector: Civil }\end{array}$ & $\begin{array}{l}2 \text { interviews: } \\
\text { - Head of BIM department } \\
\text { - BIM specialist }\end{array}$ & & \\
\hline $\begin{array}{l}\text { Case } 9 \\
\text { Sector: Buildings }\end{array}$ & $\begin{array}{l}2 \text { interviews: } \\
\text { - Information manager } \\
\text { - BIM coordinator }\end{array}$ & & \\
\hline
\end{tabular}




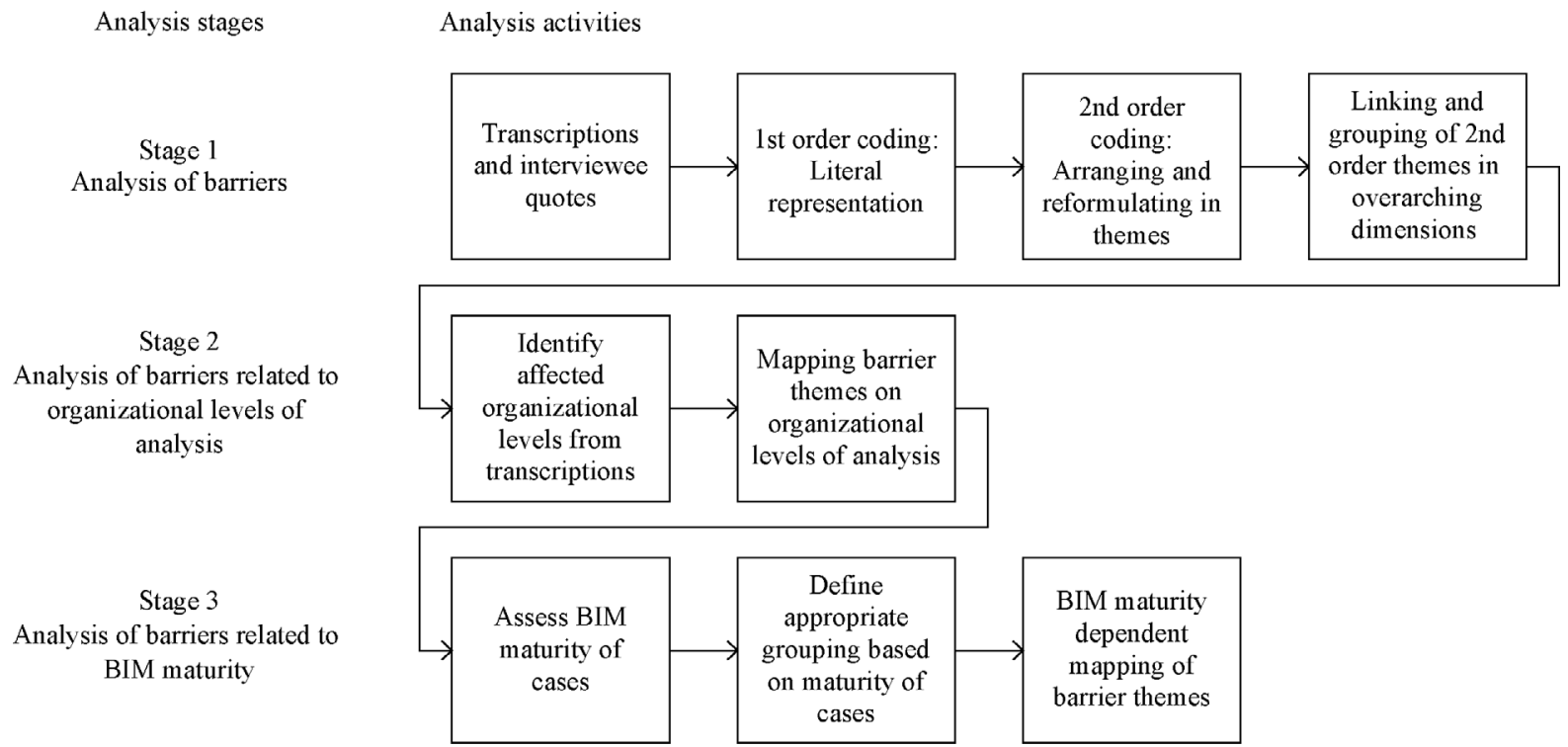

Fig. 2 Visualization of the data analysis stages.

aspects of BIM. Afterward, we checked whether a case could be assigned to a relatively low, relatively high, or average BIM maturity group. In this process, we calculated the average BIM maturity score for each case and the overall average and standard deviation. We used the outcomes to select two low- and two high-scoring subcases for a further in-depth analysis on the impact of BIM maturity on the barriers to BIM implementation and use. We used our in-depth interview data to understand the dominant barriers that appeared across different BIM maturity groupings, which we then visualized through a BIM maturity-dependent mapping of barriers. In this way, we could build our theory on the extent and types of barriers being faced by organizations with varying degrees of BIM maturity. These insights gave us some ideas on how to reduce those barriers that matched the BIM maturity level of an organization.

To validate the final outcomes, we organized a feedback session with our key informants to present them our findings and ask for their feedback. We further interpreted our findings by comparing them with those presented in the literature. We then summarized our research outcomes in the form of propositions that can be tested in future research.

\section{Results}

\subsection{BIM barriers}

We used our interview data on the barriers to BIM implementation and use to identify first-order codes which, after further analysis, could be grouped into second-order themes. We then drew up overarching barrier dimensions on the basis of these themes. Figure 3 shows the resulting data structure with (from left to right) first-order concepts, second-order themes, and overarching dimensions. In this section, we explain these overarching dimensions and their second-order themes and provide representative first-order quotes.

In explaining the barrier themes, we also considered their relationships with different organizational levels as identified from the interview data. From our data analysis and the predefinitions presented in the methodology section, we identified a top management level, an IT department and BIM department level, a middle management and project management level, a project team level, and an external level. Figure 4 shows the barrier themes and the overarching dimensions from the data structure in relation to the affected organizational levels.

\subsection{People who make it happen}

The core structure of barriers can be related to people, their resistance to change, their BIM capability, and their lack of time for implementing or learning BIM.

(a) Resistance to changing to BIM

This aspect is important across all organizational levels from top management down to the shop floor where projects are being worked upon. Resistance to adopt BIM was encapsulated in the following remark shared by a BIM department manager:

"It is all about change management at the end of the day. So my real function actually is managing change."

Overall, our informants firmly stressed that people are, 
1st order concepts

2nd order themes

Overarching dimensions

People are resistant to change

No intrinsic motivation to change to BIM

People won't embrace BIM unless you show them what the benefits are

Disciplines stick to traditional methods proven successful in the past

No ownership and drive to change

Finding the balance between desired pace of change and change capability

Create the need and motivation for people to make use of BIM

People hold on to flexibility in deciding their own way of doing things

Ignorance regarding needs and benefits of BIM

BIM performance is limited by project team competences

Not making good use of available software and tools

Shortage of good qualified people from the market and universities

Not able to prove the return on investment

No good e-learning programme available

Insufficient knowledge and proactive attitude

Not enough time to learn and start to use BIM

Maturing in BIM is time consuming and takes years

Insufficient capacity to support full BIM implementation

Insufficient human resources made available to implement BIM in projects

Insufficient competence building across projects

Lessons learnt not well-shared

Challenge to upscale the use of BIM to the whole organization in a way they recognize their need

Platforms for knowledge sharing not well-used

Not sufficiently expressing their BIM expectations to middle management Insufficient steering on BIM implementation

Measured response of the board with regard to change from BIM

Older generation has authority and experience, but no innovation power

Limited change capacity of older generation

Older generation will only gradually be replaced by more digital savvy

younger generation

Older generation not used to more structured way of working

Autonomy of project manager or director to determine BIM approach Decided on approach by project manager affects whole project team

Autonomous functioning of projects
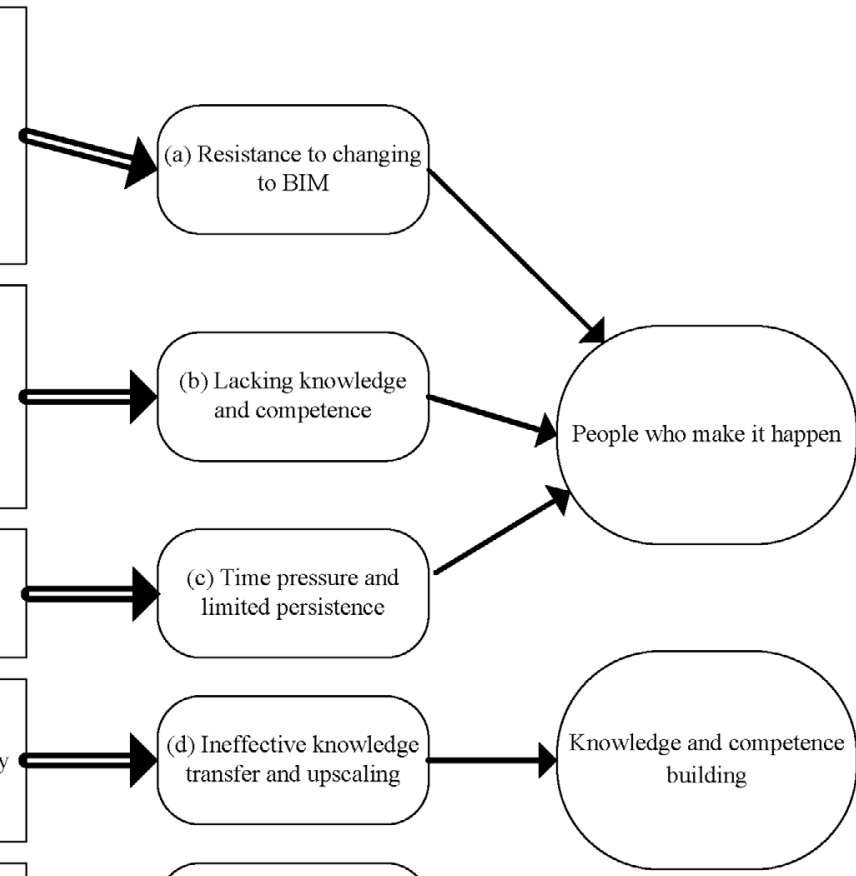

Security precautions limit data accessibility

Technical challenges

Internet connection on remote locations

Interoperability of software

Not one approach for all projects at once

Limited standardization of processes

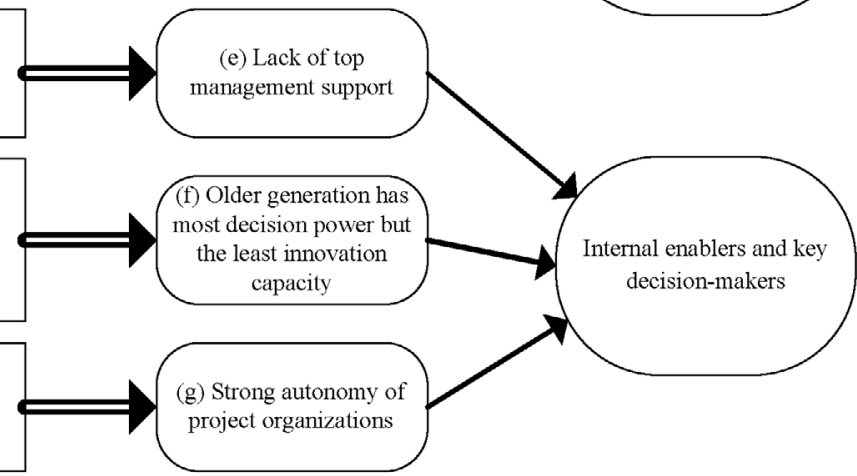

Not able to build on the information from suppliers

Insufficient knowledge and competence of supply chain partners

Clients do not request BIM or do not know what to achieve with it

Lacking BIM coordination on projects from clients
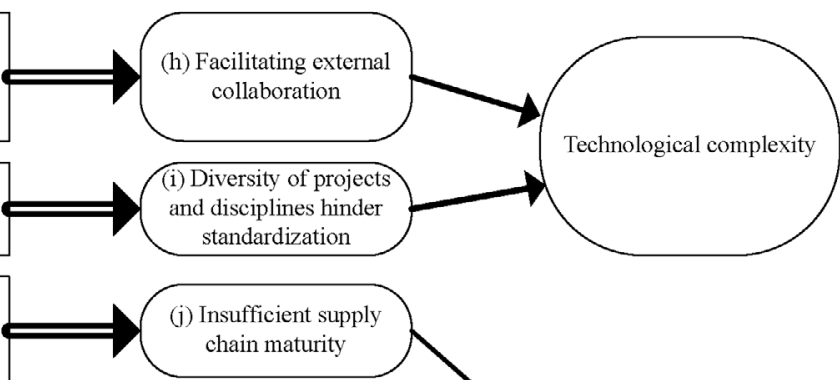

Insufficiently developed and widely adopted standard approaches for data

exchange

Limited quality of open standards

Dispersed use and interpretation of standards

Software tools do not match construction activities

Aligning available technology to project goals is complicated

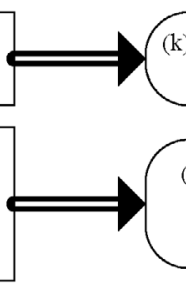

(k) Insufficient maturity of clients

1) Poorly defined or implemented open standards

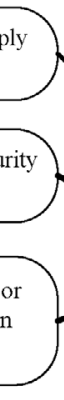

(m) Software and tools are not appropriate for the project goals and activities

Fig. 3 Data structure. 


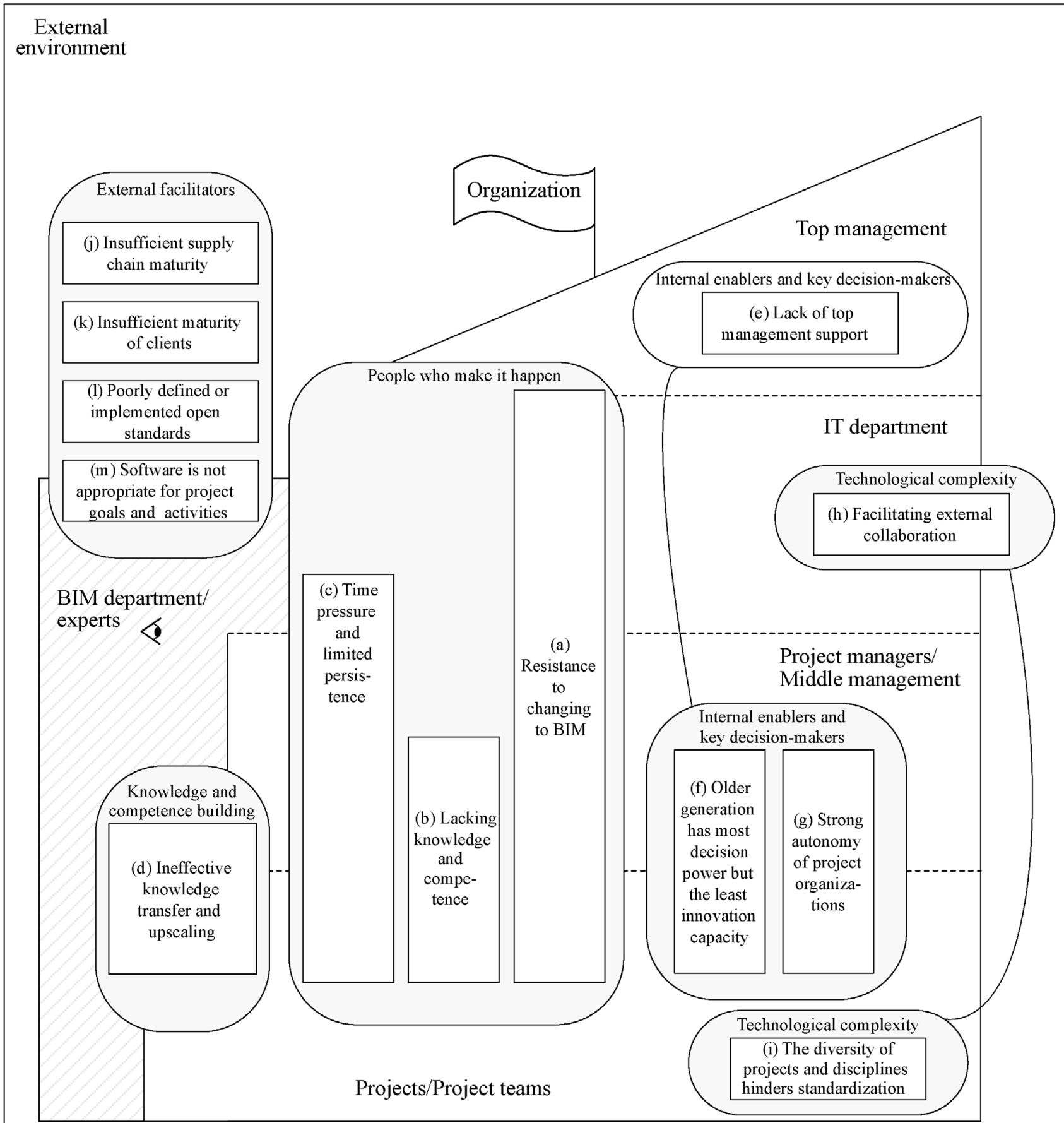

Fig. 4 Generic picture of BIM implementation barriers plotted against different organizational levels, including data from all cases.

in principle, resistant to change, especially when such change concerns their own day-to-day activities. These people tend to stick to the traditional paper-based or lessstructured way of doing things when they have authority to decide on these matters themselves. As explained by one of our respondents, people sometimes spend half of their lives using traditional systems and working practices:
"People have their own way of doing things that they are most comfortable with. It is also a way that brought success to the industry for many, many years. So they do not see the requirement for digitization as being that important. They will try and use an awful lot of excuses not to digitize." 
The only way to convince these people to use BIM is by showing them its benefits or, as one of our informants said, "You have to create a need for using BIM, otherwise people will not embrace it". Resistance to change is often unintentionally strengthened by BIM experts and managers who aim for a rapid transition to BIM. These people must be careful when deciding what to change, why to change it, and how to roll these changes out in the business. Given that an overly rapid change can result in misconceptions and disappointments, people may lose their belief in BIM. Therefore, a good fit must be ensured between the capability of people to change and the proposed pace of change.

Another important resistance mechanism comes into play when the resistance to change of a key person, such as a project manager, is easily transferred to others who may or may not be directly involved in all developments. Other project employees may not easily oppose these key people as they have the largest ownership and responsibility in project organization, specifically in the approaches taken and the extent of BIM use. Most people do not have such level of ownership or intrinsic motivation to be able to change their working methods.

"You cannot just walk into an organization and say: 'Be digital, it is good for you.' You have to show people. We have to earn their trust. They will only ever realize the benefits of being digital when being digital is a day-to-day thing for everybody; not just having a department that is digital. It should be business as usual."

\section{(b) Lacking knowledge and competence}

A very prominent barrier to BIM implementation and use is lack of knowledge and competence, which can take many forms. First, the inadequate knowledge and competence of project teams hinder BIM performance and implementation. Such limitation not only poses a problem at the project level but challenges the entire organization, including the middle-management who must decide whether BIM should be used and how such technology should be applied.

Many respondents have attributed the lack of knowledge and competence in their organizations to the shortage of qualified people and the difficulty in training people. Moreover, when hiring people, organizations tend to ignore the importance of BIM competences. The knowledge and competences of people should match the vision and future direction of BIM. This HR component is captured in the following quote:

"We, as technicians, tend to focus on technical aspects. However, we need to be aware of the huge human resource component of BIM implementation, which starts from educating the people we hire or currently have. It also takes into account the future directions of our business when selecting new people."

Given the apparent difficulty in training people, the quality of available e-learning programs was criticized during the interviews. If e-learning programs were better tailored to the needs of different disciplines in an organization and were more user friendly, then they can be seen as key motivators for people to learn and apply BIM in their daily activities. Notably, the competences in using basic tools and frequently used software were also limited:

"Some people think that we have to buy software, but we have enough software that we just do not make good use of. When you show people what they can do with the software, it kind of changes their life. They say: 'Wow, I have been doing this manually.' So, are we getting the most out of our current software solutions? Most people's answer would be no."

The interviewees also pointed toward the limited understanding of the tangible benefits that BIM can bring to their projects. Most of the time, the investments required for BIM are clear, whereas its return on investments remains unknown. The case study organization launched many initiatives to produce evidence on the advantages of using BIM in their projects but faced difficulties in distinguishing the impact of BIM from that of other factors that influence project performance.

\section{(c) Time pressure and limited persistence}

Time pressure is considered a barrier to BIM implementation and use given that accelerating the adoption of BIM often creates additional responsibilities for people, which may lead to time pressure and demotivation. Although BIM is supposed to bring benefits in the longterm, sometimes investment is required in learning about new tools, software, and work practices. Given the high pressure at the operational levels of project teams, project managers, and the BIM department, these people do not always have the time or support they need to use BIM. Time pressure is also related to people's persistence in using BIM when they feel that their implementation of BIM is not worthwhile. The following quote captures this tension between time and persistence:

"Say for example that a project engineer still has a lot to learn about BIM, so he starts to undergo training and gain in-depth knowledge about BIM. This probably means that he has to spend additional 10 hours a week for learning alongside his regular project activities. Although he might end up gaining the results he expected from BIM, the question lies in whether this project engineer has become 
happier and more enthusiastic about BIM after his experience. I have experienced several cases in which such people said they would not go through this process again because of the chaos and additional workload it caused. This is of course a missed opportunity in our effort to motivate people to use BIM."

Given the time pressure imposed by projects, an organization cannot simply switch to BIM because people are operationally fully occupied and have limited time for development trajectories. Therefore, patience is necessary because upscaling to a more extensive BIM use can, in most cases, only be incorporated in a later project.

Time pressure can also be related to the traditional roles of people within their organizations. Implementing BIM may sometimes create additional responsibilities (e.g., highly structured document management or design coordination) that people must fulfill along with their present roles. Even if people are keen to take on these responsibilities given their competences, they may not always be able to because of time pressure.

The interviewees also reflected on the efforts of their own departments in expanding their use of BIM to complete their projects, provide on-the-job support to project teams, and convince people to use this approach. One interviewee argued that the current capacity of the BIM department matched the project needs from the perspective of the client's requirements. However, additional resources are required to further upscale BIM and structurally work on innovation:

"If we really want to achieve what the firm's strategy requires, we would need a lot more. We probably would have to hire 10 more people for our department."

\subsection{Knowledge and competence building}

The next overarching dimension is knowledge and competence building, which involves transferring and upscaling knowledge on BIM across different projects to improve the institutionalization of such knowledge.

\section{(d) Ineffective knowledge transfer and upscaling}

One problem related to knowledge transfer and upscaling as identified from the interview data lies in the projectbased culture of the construction industry. Firms in this industry initially focus on winning a project contract at the tender stage and then execute the project before quickly pulling back and quickly moving on to their next project. One interviewee explained this project-level barrier:

"The project team, as a tight group of people, takes the lessons they learned from one project to another. They can apply that knowledge and get better progressively, but the sharing of that knowledge to other parts of the business is not where it needs to be."

This lack of knowledge sharing and competence building may also be ascribed to the means or tools by which knowledge and competence can be effectively shared or built. A digital platform for knowledge sharing has been deemed ineffective by an interviewee:

"Even if we have a good platform, most of our people are not interested in sitting down in front of a web page and spending time learning."

Therefore, the question here is how to bring knowledge to people who are busy working on their projects while simultaneously make them realize the benefits of such knowledge. One challenge perceived at the BIM department level is matching the available technology and methods to the specific needs of various job profiles:

"We have had discussions about starting a campaign where we try to increase people's awareness of the type of technology that is available to them on the site and sell it to them on their competence level. Not on our level, because we see technology in a very different way to maybe what a foreman, carpenter, or metal worker would. They all want different things. So, we need to be a bit more cognizant, a bit more aware of what people are looking for."

Other initiatives at the middle-management level, such as organizing meetings with project and design managers, have struggled with poor attendance and have not produced their intended impact because those people who do not attend such meetings are mostly unaware of the importance of knowledge sharing. On the contrary, those people who are already trying their best to stimulate knowledge sharing on their projects are the ones who participate the most in these meetings.

\subsection{Internal enablers and key decision-makers}

This overarching dimension relates to the key people in an organization who play leading or steering roles in facilitating BIM implementation and use throughout their organization. This dimension involves top management support, the autonomy of middle management in project organizations, and the impact of age distribution in an organization.

\section{(e) Lack of top management support}

Support from top management was operationalized in the case organization in the form of providing resources for BIM implementation and supporting BIM in spoken pronouncements. Although most of the interviewees agreed that verbal support was generally present in their organization, the organizational unit's top management 
could more firmly speak out about their expectations regarding BIM to middle management. Specifically, top management should issue concrete targets through which the middle management could contribute to the corporate strategy in the projects for which they are accountable. One interviewee criticized the high degree of freedom in people's jobs:

"Although I like freedom myself, the top management currently allows too much freedom for project managers to decide on which BIM approach should they adopt in their projects. Why should I, given my role in the BIM department, convince a project team to use BIM? Why is it not the other way around, so that the project team has to explain to top management why they are not using BIM in accordance with the corporate strategy? Rules and boundaries are currently lacking in the BIM playing field."

In the same vein, one interviewee highlighted the risks that may emerge when the top management does not steer BIM implementation efforts in the organization. If the BIM guidance from the top level is insufficient, then "people will continue working on their project islands and will focus on their own uncoordinated developments". In other words, the top management must facilitate internal boundary spanning to make sure that people within the organization will share BIM developments not only within their respective departments or projects but throughout the entire organization.

The interview data also highlighted that the riskavoiding attitude of top management restrained BIM implementation. Nevertheless, the board had signed up to BIM and appreciated what BIM could do to the organization. However, their responses to BIM implementation were generally unsatisfactory because of their feared negative consequences of a very rapid change.

(f) The older generation has the most decision power but the least innovation capacity

The age distribution within an organization also created a barrier to BIM implementation and use. The interviewees distinguished a younger generation, a gap in the middle, and an older generation of people within their organization. The "youngsters" are the ones with the brightest new ideas, and even if they are more innovative than their older counterparts, they lack the experience to implement their ideas. By contrast, the older generation, who generally have at least 10 to 15 years of experience, mostly occupy decision-making middle-management positions and are less knowledgeable about innovative digital technologies, thereby discouraging them from introducing and using these technologies in their organization. In other words, the older generation has a limited capacity to change and, as explained by one interviewee, the change process will only gradually take place:

"Time is a great issue as well. You could say, whether you like it or not, it could take 10 years for older people to leave and be replaced by a younger generation and also for people to be trained in the way of the business and adopt a digital approach."

Some characteristics specific to each age group within an organization were also identified. For example, among project managers, the more structured ones embrace new technologies much easier, whereas the more chaotic ones face difficulties in conforming to a highly structured and formalized way of working.

\section{(g) Strong autonomy of project organizations}

Similar to the aforementioned barrier, the strong autonomy of project organizations is mainly reflected at the middle-management level. Our interviewees viewed this level as the link that connects top management with the BIM department on the one side and with the project teams on the other. Project managers are accountable for both the success and risks of their projects and, as such, have considerable influence in deciding how they should approach their projects. The whole project team is more or less trapped within the BIM approach determined by their project manager. One interviewee described this barrier as follows:

"The project managers have full responsibility for their projects; they have decisive power. This means that within our organization, these people have the power to decide to what extent BIM should be applied in our projects. Of course, in some cases, this turns out positively, but we also adopt rather conventional approaches to our projects."

This barrier implies that construction firms consist of many project organizations that are separately steered and managed and have specific extents of BIM use.

The widespread location of projects is another factor that influences the autonomy of project organizations. Given their distant functions, project organizations located further away from the head office have a greater degree of independence:

"We expect project organizations to operate independently. They have to deal with their own problems. Consequently, these project organizations do not allow much steering from the head office."

The interviewees were aware of the differences between their perspectives on BIM and those of their project managers, thereby creating a gap between their desired BIM use and that being practiced in their organization. One 
interviewee used a striking metaphor to explain these divergent perceptions toward BIM:

"Imagine that I need to be at a known destination in half an hour. I will take my car, as I always do. Now someone proposes to try something new, the Hyperloop, which will probably take me to my destination in 15 minutes. However, according to my contract, I need to be there in 30 minutes. So, do I trust that other person enough to take his suggestion and to accept the associated risks and uncertainties? That is exactly what we ask from project managers. We should not be surprised if they tend to rely on more traditional methods."

\subsection{Technological complexity}

Technological complexity mainly involves the challenges in facilitating external collaboration with other parties or disciplines and the complexity stemming from the diversity and uniqueness of projects.

\section{(h) Facilitating external collaboration}

The exchange of data with external parties is primarily hindered by security precautions, such as the use of firewalls. Consequently, IT departments experience many challenges in making data accessible among different parties. Workarounds are being used in practice, but they mostly undermine security. File-based approaches were also mentioned by the interviewees as a way through which external data are exchanged. However, they would rather opt for online services or cloud-based collaboration.

The success of external collaboration at project locations also depends on the quality of Internet connection. Given that some projects are situated in very remote locations, Internet speed can also create a barrier to data exchange:

"We do have high-end laptops and facilities, such as double screens and high-resolution monitors.

However, these devices are useless if we have slow Internet cables attached to them."

The interviewees argued that collaborating with other parties is hindered by the limited interoperability of BIM software. Therefore, linking information from various software packages used for design, calculation, and project control presents another challenge that can reduce the quality and reliability of the exchanged information and may require a highly extensive monitoring and checking of data.

(i) The diversity of projects and disciplines hinders standardization

The second technological challenge refers to the uniqueness and diversity of departments and projects. In principle, the efforts of the BIM department are aimed at the ongoing BIM developments at the project level. However, only few projects can benefit from the implementation of these new developments given the difficulty in applying BIM across all projects at the same time and in a similar manner. BIM developments tend to contradict the scope of some projects and, in practical terms, implementation is limited by the supportive capacity of the BIM department.

The specific process definitions for various disciplines within an organization can also hinder standardization:

"Each division and department has their own processes that work well for them because they have optimized them for their own needs. As soon as you want to use standardized systems across the organization, it creates a problem. So, the centralized standard for processes is not used in every project, at least not in detail."

\subsection{External facilitators}

We also identified some factors that threaten BIM implementation and use yet cannot be directly influenced by internal processes within the case study organization. These factors can best be regarded as facilitators or conditions for internal BIM processes. We identified four main themes from our analysis, namely, the BIM maturity of supply chain partners, the BIM maturity of clients, the definition and implementation of open standards, and the appropriateness of available software to the project goals and activities.

(j) Insufficient supply chain maturity

Our case study firm, as a general contractor, greatly depends on its projects and information from its subcontractors and suppliers. However, not all supply chain partners have equal knowledge and experience with BIM as pointed out by an interviewee:

"We have to build on the information we get from our supply chain partners. However, we can only do so if the quality of information is sufficient. This is a debatable point. We often get poor-quality object libraries from our suppliers. We cannot use these in our models. Although we give these suppliers feedback and try to train our most important suppliers on how to set up an object library, we do not always get the quality we need."

Some interviewees argued that the maturity of their supply chain partners also depends on how they are procured. One interviewee shared:

"We should make a decision. Is a cheap partner good or should we spend more money and have an easier time? Do we make more money out of that? That is a hard thing to figure out." 
(k) Insufficient maturity of clients

Our case study organization was involved in many projects where clients did not request for BIM usage. In these cases, the project was either carried out by using a traditional approach or the project team had to convince their clients regarding the added value that BIM can provide to their project. The insufficient BIM maturity of clients may also be manifested in situations where clients request for BIM use but have no idea about its benefits or how to use the information in the operation and maintenance phases. One interviewee emphasized the need for a mature and well-educated client in terms of BIM:

"We need a well-educated client. We need someone on the client side who is coordinating BIM, including information management, project coordination, and BIM capability of designers, before these designers engage in a project. Too often, our clients are incapable of doing these."

\section{(1) Poorly defined or implemented open standards}

Information and data exchange standards have not been well-established in the construction industry. The interviewees argued that the construction sector had only recently recognized the importance of such standards, whereas other branches, such as the mechanical, electrical, and plumbing sectors, had done so years earlier. As a result, different parties have varying perceptions toward object naming, and the landscape of information standards is very much dispersed, thereby preventing supply chain collaboration:

"There is an ongoing discussion with the supply chain to make sure that information is presented to us in the right format. There is no standard approach. Whether you are talking to environmental agencies, to rail infrastructure clients, or to road infrastructure clients, they all have different ideas of what they want, the format they want it in, and the information that is contained in it. Even the divisions within these organizations have yet to reach firm agreements with one another on what they want. This makes it very hard for us to engage with the supply chain in the way we prefer."

Even if sector standards are available, their inconsistent interpretation and use create another barrier to BIM implementation and use. Setting up specific BIM arrangements for different clients hinders the standardization of processes and contracts and absorbs the capacity of a supportive BIM department that can otherwise be used to ensure a more value-adding BIM use.

The interviewees saw the quality of the Industry Foundation Classes (IFC) data exchange standard as another barrier. Some of them argued that the quality of this standard should be better controlled. Additionally, the case study organization often receives discipline-specific models in open standard formats that are not thoroughly checked by suppliers before being exchanged. Given that this practice can propagate serious errors into the overarching BIM model, solid agreements must be reached on specific native data exchange formats. The lack of a solid standard also prevented an open exchange, use, and reuse of information in a BIM environment.

(m) Software and tools are not appropriate for the project goals and activities

The interviewees revealed that BIM is increasingly being used in construction sites. All types of digital technologies are finding their way into these sites. For instance, construction workers have begun to use tablets to gain insights into their designs or to facilitate site inspections. However, the functionality of these technologies was also criticized by the interviewees from the supporting BIM departments. In terms of software, they felt that the main packages being used in their organization did not sufficiently support onsite employees in their construction activities. These software packages could only present the final situation, which limits the added value of BIM software in the construction phase. The interviewees wanted to have a software package that guides them step by step throughout the construction process. This software can also benefit the creation of a consistent and structured approach that can contribute to improved quality and status control. The interviewees also highlighted the poor user-friendliness of hardware, such as tablets, especially in situations where employees need to walk around on-site with these devices and work precisely with touch screens.

The interviewees shared that their project teams and BIM departments face challenges resulting from the poor fit between their software and project goals:

"There is not one software package that provides a perfect or desired BIM solution for each situation. Considering the goals and applications in a specific project, a software package might, for instance, not be favorable for 4D modelling linking a 3D model to a construction plan. Therefore, we have to be careful when linking technology and software to the goals and activities of a project. This requires not only flexibility in people but also skills to work with different software packages."

\subsection{Barriers related to BIM maturity}

We added another dimension to our analysis of the barriers to BIM implementation and use by evaluating the BIM maturity scores in our individual cases. These scores can 
help us understand whether we should expect differences in the barriers being faced by companies with low and relatively high BIM maturities. We also gained insights into the organizational levels on which these barriers influence the outcomes of organizations with different BIM maturities.

By analyzing the average BIM maturity score across our main criteria (i.e., strategy, organization and project structure, people and culture, processes, IT infrastructure, and data structure), we identified two cases that scored significantly above average and two cases that scored significantly below average. We considered a case to be significantly higher or lower if its average BIM maturity differed by at least one standard deviation $(\sigma=0.5)$ from the average of all cases. Afterward, we grouped those cases with a low maturity (Cases 6 and 9) and those with a high maturity (Cases 2 and 7). The remaining cases were considered average maturity. Table 2 shows the calculations and the grouping of cases. Case 1 was at the borderline for being included in the low maturity group. We therefore analyzed how including Case 1 would affect the low maturity group, but given that the outcomes matched with the findings for Cases 6 and 9, we limited ourselves to these two cases.

By examining the BIM maturity level of the cases in detail, we could also assess BIM maturity on the basis of the six main criteria. We plotted in Fig. 5 the maturity scores for each case for the six main criteria of the BIM maturity model to further understand how the average BIM
Table 2 Grouping of cases on the basis of their BIM maturity scores

\begin{tabular}{lccc}
\hline Cases & Average maturity & Average maturity $-\mu$ & Grouping \\
\hline Case 1 & 2.7 & -0.4 & Average maturity \\
Case 2 & 4.0 & 0.9 & High maturity \\
Case 3 & 3.4 & 0.3 & Average maturity \\
Case 4 & 3.2 & 0.1 & Average maturity \\
Case 5 & 2.8 & -0.3 & Average maturity \\
Case 6 & 2.6 & -0.5 & Low maturity \\
Case 7 & 3.8 & 0.7 & High maturity \\
Case 8 & 3.4 & 0.3 & Average maturity \\
Case 9 & 2.4 & -0.7 & Low maturity \\
Average of & 3.1 & & \\
all cases $(\mu)$ & & & \\
Standard & 0.5 & & \\
deviation $(\sigma)$ & & & \\
\hline
\end{tabular}

maturity is built up and how much variance is present in our data set with respect to our cases and criteria. We can immediately see that the BIM maturity scores for IT infrastructure are relatively high in all cases, thereby supporting the view of our interviewees who argued that IT is not their main concern in their organizational transition toward BIM. Furthermore, those cases with the highest average BIM maturity levels (Table 2) did not score the highest for IT infrastructure. However, one of the low maturity cases scored highest for IT infrastructure. If we

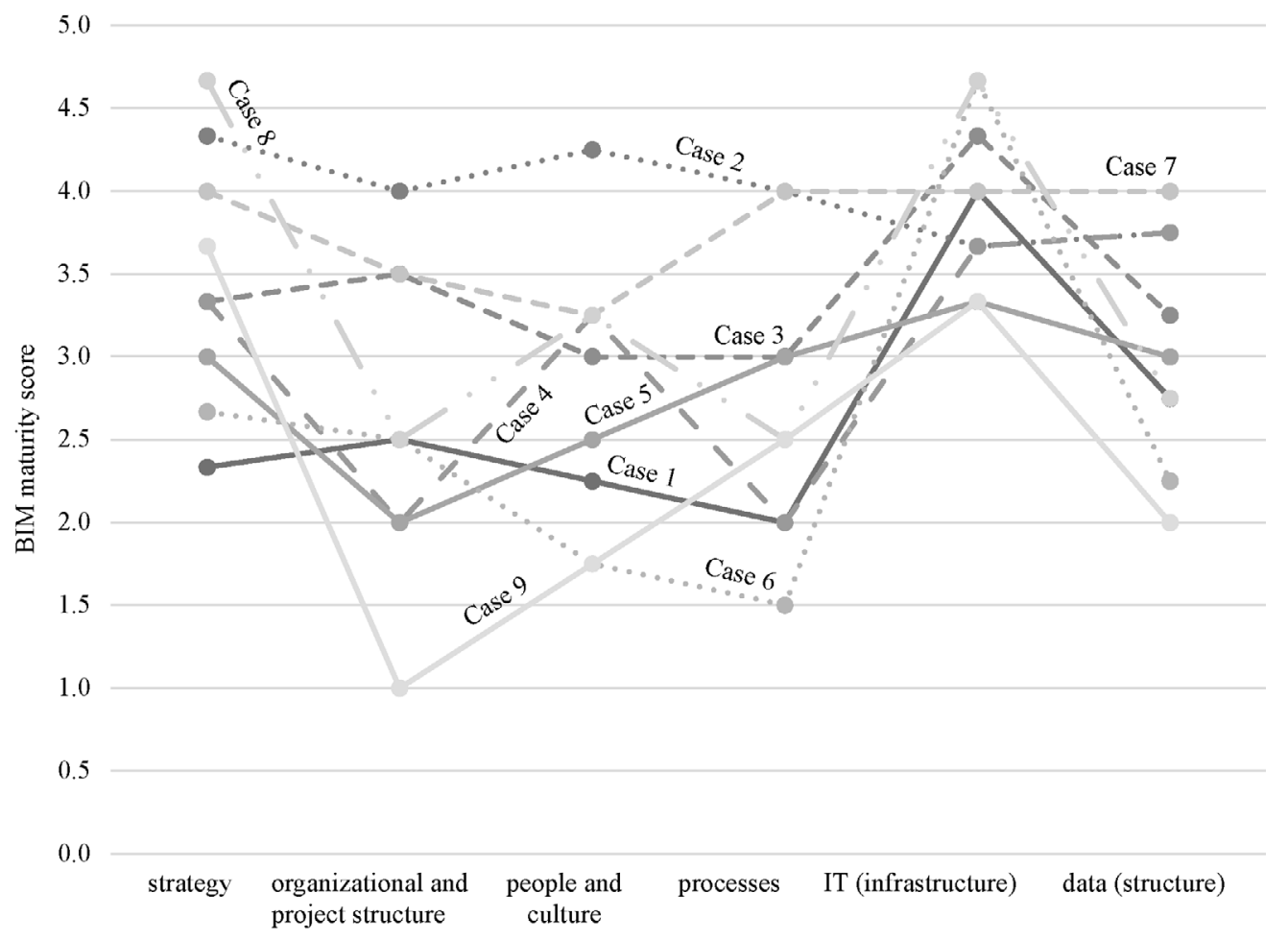

Fig. 5 BIM maturity scores per case and per criterion of the BIM maturity model. 
were to leave IT infrastructure out of our overall BIM maturity scores due to these observations, then the classification of cases to low or high maturity groups is more explicit.

We then compared the barriers identified in the low, average, and high maturity cases and revealed that 10 of the 13 identified barrier themes applied to cases from all 3 BIM maturity groups. We also found that the barrier themes plotted in Fig. 4 reflect those cases with an average BIM maturity. Only three barrier themes were linked to a specific BIM maturity group, namely, limited top management support, inappropriateness of software and tools for project goals, and poorly defined or implemented open standards. The first of these themes (limited management support) was mentioned by the interviewees from the low and average BIM maturity groups (Fig. 6) but not by the interviewees from the high BIM maturity group (Fig. 7). One interviewee from the high BIM maturity group described their management support as follows:

"We do have a lot of support from top management, who clearly communicates to us why the company has to implement BIM. This has made a huge difference for us. Due to their top-down support and because of some good bottom-up BIM experiences from our project sites, people have become increasingly aware of the benefits of BIM, which accelerates its implementation."

A striking result is the external character of the two barriers that we did not identify in the low maturity cases, being the inappropriateness of software and tools for project goals and poorly defined or implemented open standards, as can be seen in Fig. 7. Both of these barriers relate to external parties and, as such, go beyond the sphere of influence of the interviewees. We noticed that the interviewees from the high BIM maturity cases referred to these external barriers because they often outperform other parties in multi-organizational projects or have to take a leading role in BIM, thereby expanding those barriers that high maturity organizations experience in these contexts. By contrast, the low maturity cases seem to focus first and foremost on improving their internal BIM maturity. The interviewees from these cases stated that their concerns were mainly related to internal factors, such as the knowledge and competences of people.

The demands placed on software tend to be higher in the high maturity cases, which are known for their highly extensive and professional use of BIM. These units have sometimes already reached the limits or potential of their current software solutions. The interviewees from these cases were more reflective and critical of their software solutions and, because of that, could propose some desirable future scenarios:

"We tend to see the availability of all information in a 3D model on a tablet as an advantage for foremen, but it is not. Rather, the question is how to make sure that these people get the right information for their tasks at the right moment. Not that someone has to look at a tablet while standing on the scaffolding. Considering safety, this is something we do not want either."

The interviewees from the high maturity group more often engaged in discussions with software vendors to further improve their BIM software and to improve the fit between software and construction activities.

\section{Discussion}

We identified from previous research a need to explore the barriers to BIM implementation and use in relation to the organizational levels affected and the level of organizational BIM maturity. The adopted multiple case study approach provided in-depth insights within the context of the case study construction organization and was aimed at theory building by taking a new, fresh perspective toward the barriers preventing BIM implementation and use (Eisenhardt, 1989). The results of this study contribute to the knowledge and understanding of those barriers that organizations face during the complex process of BIM implementation and use. Practitioners can use these insights to develop measures for addressing these barriers on specific organizational levels while taking into account the BIM maturity of their organizations. In doing so, these measures can be more effective, and the implementation and use of BIM can be stimulated.

We use our case study results to discuss the most interesting findings and to develop testable hypotheses. First, we found that the most dominant type of barrier is related to people's motivation, competence, and capacity to implement BIM. This barrier theme was emphasized by the interviewees from all cases and was not limited to a specific organizational level; rather, this problem crosses all organizational levels from top to middle management (through organizational departments) and is also prevalent at the project level. We therefore propose:

Proposition 1. The core group of barriers to BIM implementation and use, which cross all organizational levels, is formed by people-related aspects linked to motivation, competence, and capacity to switch to BIM.

Although BIM has a rather technical connotation, its success is largely bounded by people and organizational aspects. Our proposition is consistent with the existing theory that highlights the importance of people in the broader contexts of innovation adoption, IT use, and organizational change processes. For instance, Jones et al. (2005) found that organization culture and change capability affect the success of change implementation 


\section{External}

environment

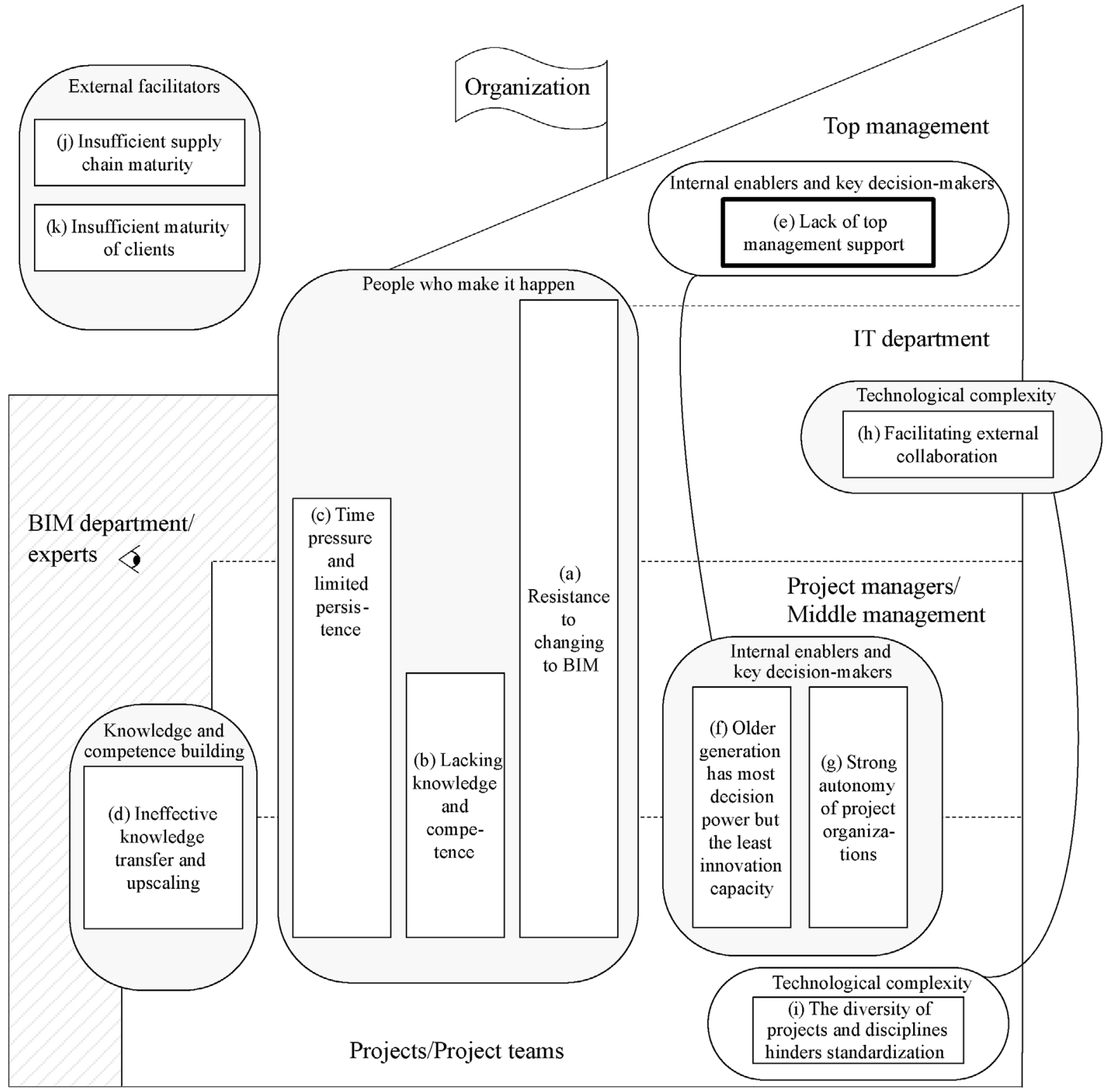

Fig. 6 BIM implementation barriers plotted against organizational levels for the low BIM maturity cases. Characteristic barrier themes are highlighted in bold. 
External

environment

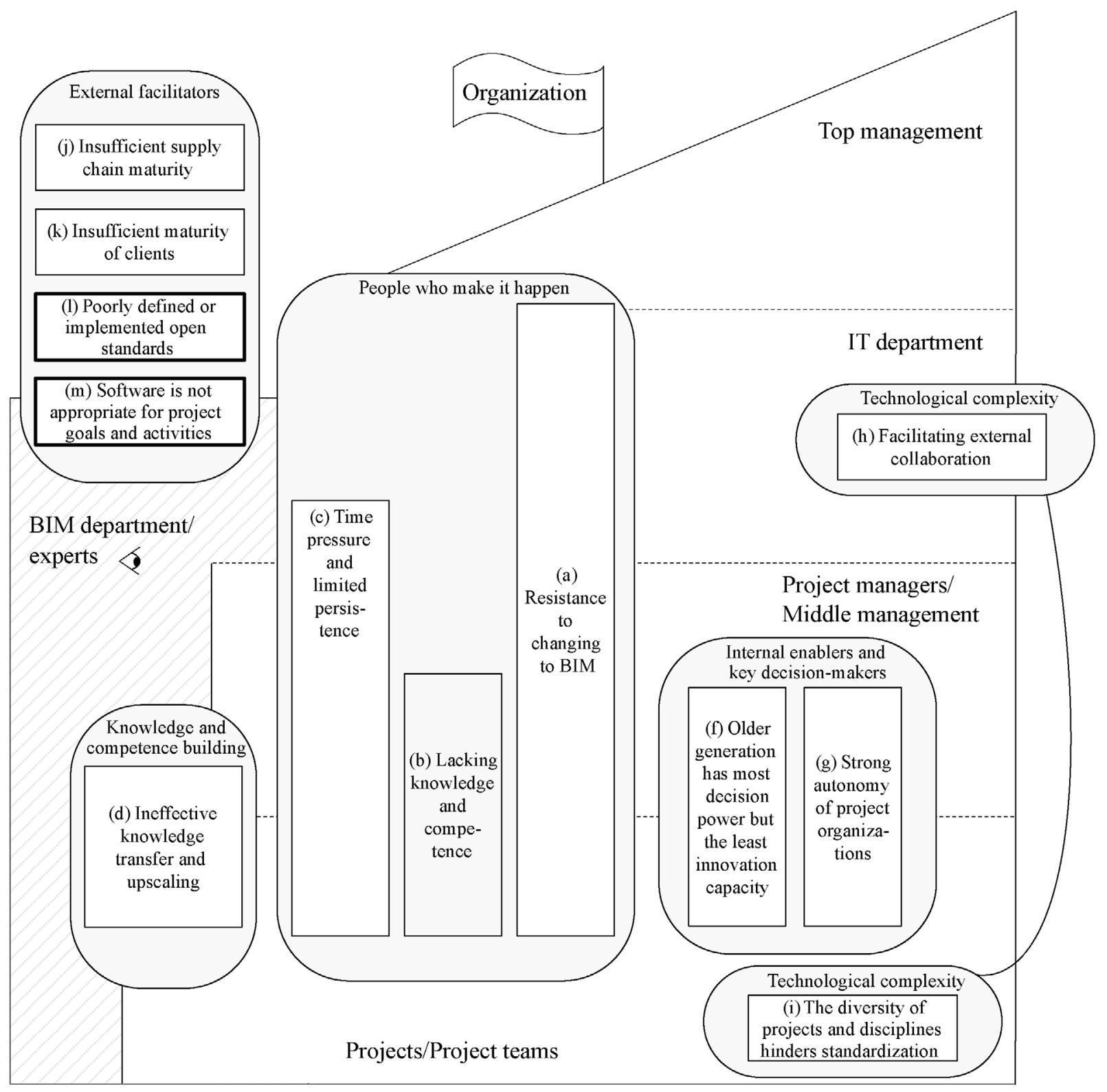

Fig. 7 BIM implementation barriers plotted against organizational levels for the high BIM maturity cases. Characteristic barrier themes are highlighted in bold. 
and the employees' perceived readiness for change. The importance of barrier themes related to motivation and capability was also supported by Holt et al. (2007), who suggested that readiness for change is influenced by multiple factors, including the capability to implement the change and the perceived value of the proposed change. They also identified management support, or their commitment to implementing the change, as an influential factor, which resonates with our finding that a limited management support blocks the achievement of higher levels of BIM implementation and maturity in an organization. To address the important barriers related to competence and motivation, we should explicitly state the required competences for BIM use. By incorporating these competences into function descriptions and personal training programs, organizations can build a structure that can motivate people to perceive BIM as part of their daily work.

Although we found barriers across all organizational levels, these barriers predominantly appeared at the middle-management level and at the boundary of the project level. Therefore, the middle-management level plays a crucial role in influencing the barriers to BIM implementation and use. We then propose:

Proposition 2. The middle-management level plays a key role in influencing the transition to BIM in projects and in transferring BIM knowledge and experience from one project to another.

Although research in the construction field has not specifically considered the role of middle-management in BIM implementation, broader management studies on strategy implementation have done so. For instance, Guth and MacMillan (1986) concluded that when the selfinterests of middle managers are at stake, they may redirect, delay, or worsen the implementation of a strategy. In our multiple case study, we observed similar behavior from middle-management whose self-interest reflects their overall responsibility and accountability for the performance of their projects. Although many of our interviewees placed middle-management in a poor light, we perceive that the restrained behavior of the middlemanagement toward BIM implementation is understandable. The organizational structure of typical construction firms with autonomous project organizations can be considered a driver of their middle-management's conservative attitudes toward change. Similar to Guth and MacMillan (1986), Tarakci et al. (2018) found that the negative behavior of middle-management toward strategic initiatives can be overcome by increasing their sense of identification with their organization, which can outweigh their individual drivers. This implies our case study firm should create an organizational culture that supports BIM implementation and use and ensure that its middlemanagement is willing to embrace this organizational mindset. Given that the middle-management occupies a central position in different organizational processes (Wooldridge et al., 2008), we recommend future studies on BIM implementation to focus on this level.

We also examined the relationship between BIM maturity and the extent and type of barriers faced by organizations. The spread in BIM maturity within our cases allowed us to select and compare two cases with low BIM maturity and two cases with high BIM maturity. Our case study results suggest that most barriers to BIM implementation and use occur irrespective of the level of organizational BIM maturity save for a few notable exceptions.

First, limited management support was frequently mentioned as a barrier in the cases with low BIM maturity. Management support is a directive voice that can stimulate an organization's transition to BIM and is essential in the early stages of BIM implementation. Specifically, this directive voice can motivate the majority of those employees who lack the intrinsic motivation to use BIM. We therefore propose:

Proposition 3a. A lack of top management support is an indicator of a low BIM maturity in organizations, thereby highlighting its importance as an essential condition for BIM maturity growth.

Second, the high maturity cases often pointed toward barriers outside their organization, such as the appropriateness of BIM software or tools for construction activities and the poor definition and adoption of standards. We propose the following:

Proposition 3b. Organizations with higher BIM maturity have higher demands when working in collaborative project environments and, as such, experience more external barriers to BIM implementation, including limited software capabilities and poor availability and adoption of standards.

Our interview data revealed that those organizations with higher BIM maturity aim to work closely with the supply chain to maximize the benefits from BIM. By contrast, low BIM maturity organizations were highly dependent on the maturity of their supply chain partners instead of working with these partners in implementing BIM. Therefore, a greater maturity leads to an increased collaborative focus on BIM in which organizations become more aware of their position in the supply chain and their dependence on their supply chain partners. This argument is supported by Lockamy III and McCormack (2004) who, in their study of business process maturity, observed a focus shift from internal to inter-company as the level of organizational maturity increases. Our findings can also be understood by looking at the definition of organizational maturity. A mature organization will explicitly and 
consistently deploy its processes to effectively contribute to its business goals (CMMI Product Team, 2010; International Organization for Standardisation, 2015). Being relatively mature in a multi-organizational project environment will therefore increase supply chain demands in order to satisfy goals and expectations, which in turn can improve the supply chain orientation of organizations to align their processes with those of their partners. These partners also require attention when their limitations or weaknesses become apparent.

Our comparative analysis of BIM maturity and barriers revealed some interesting findings related to IT. All units, even those with a relatively low BIM maturity, scored relatively high on IT aspects, which agrees with the interviewees' opinions that the IT across their organization was sufficiently available and generally of an adequate standard. Therefore, the maturity of an organization's IT infrastructure does not necessarily correlate with its overall BIM maturity. In other words, IT infrastructure is not a good predictor of the type or extent of barriers being experienced by organizations in their BIM implementation and use. Instead of providing an impression of overall BIM maturity, IT infrastructure can be seen as an organizationwide condition for IT-supported processes, which include, but also go beyond, the scope of BIM. Furthermore, in practice, the IT infrastructure is traditionally considered an initial condition for BIM implementation even before the other aspects of BIM are handled.

However, as emphasized by the interviewees, those aspects related to people and the organization play decisive roles in the progress of BIM (Won et al., 2013). Taylor and Levitt (2007) argued that innovation should be aligned with the work practices of people in order to be successful. Broader studies on innovation have also emphasized the importance of the organizational context in which technological innovation is supposed to take place. Instead of introducing an innovation that overloads and burdens its employees with additional demands, an organization should provide a context where these employees can connect, share ideas, and engage with one another in a creative innovation process (Cross et al., 2016; Arena et al., 2017). Our analysis of barriers support this notion given that the most important barriers also relate to this non-technical area, including people's motivation to change and their competence in using BIM (Adriaanse et al., 2010a).

Our study has several limitations. The first limitation is inherent to the case study approach and concerns the limited generalizability of our findings. Given the limited statistical evidence we used in our study, our findings should be considered primarily within the context of the investigated case. However, we strove for theoretical generalizability by embedding our findings in existing theories and, in so doing, tried to rule out alternative explanations. As such, our propositions are designed to encourage future researchers to broaden the context of this study and to search for additional statistical evidence by employing larger samples that represent the vast diversity of organizations, disciplines, and country-specific conditions in the construction industry.

The second limitation stems from the fact that we built our theory primarily from the perspective of people working in departments responsible for BIM. Although we highly appreciated the open, reflective, and critical attitudes of our interviewees, we are aware that their perspectives were limited to the BIM implementation and use in their respective BIM departments and scope of work. However, we can justify these perspectives given the richness of the information that the employees from BIM departments can provide. These people can also provide an overview of BIM implementation in their organization from the top management level to the project level, thereby contributing to the aims of our study. Nevertheless, future studies should extend our theory by recruiting informants from different organizational levels who can critically reflect on the impact of their BIM departments. In addition, the perspective of people from the BIM department can be interpreted by looking at the relationship between their perceived barriers and the actual implementation level of BIM in their organizations. In this way, the impact of barriers on the progress of BIM implementation becomes tangible.

\section{Conclusions}

This study sheds new light on those barriers that hinder the implementation and use of BIM with respect to (1) the affected organizational levels and (2) the BIM maturity of an organization. We performed an in-depth multiple case study of nine cases from a large contracting firm. Our interviews with representatives from the BIM-supporting department provided a broad organizational perspective on those barriers experienced by the organization from the top management level down to and including the project level. In this way, we improve our understanding of both the causes and consequences of these barriers and, specifically, of those organizational levels on which actions need to be taken to overcome barriers.

Our findings highlight the dominance of barrier themes that are related to people's motivation to change to BIM, their competences in using BIM, and their capacity to make and support the transition to BIM. These barriers also stand out by their existence across all organizational levels in the investigated case. Although these barriers manifest themselves across all levels of an organization, our findings highlight the key role of the middle-management level in influencing both the transition to BIM in projects and the transfer of BIM knowledge from one project to another. Our analysis on BIM maturity revealed that limited management support only emerges as a barrier in units with low BIM maturity levels, thereby suggesting 
that such lack of support significantly hinders the BIM maturity of an organization. Meanwhile, those units with above average maturity levels predominantly showed barriers related to their external environment given that these units focus on external collaboration as a way to enhance the benefits of BIM.

Following the suggestion of Tarakci et al. (2018), we recommend future research to focus on how to effectively influence the middle-management of construction firms. Another recommendation for future research is to use our insights on BIM implementation barriers to explore preventive and counteracting measures that can be tailored to specific organizational levels and to organizational BIM maturity. Furthermore, extensive research should be conducted to support the impression that - instead of IT aspects - non-technological aspects can be used as indicators when determining the overall BIM maturity of an organization.

Our study covers only a limited period of drastic change within the construction industry. We therefore hope that other researchers leverage our findings in investigating the future progress of BIM and identifying new barriers that may arise.

Open Access This article is licensed under a Creative Commons Attribution 4.0 International License, which permits use, sharing, adaptation, distribution and reproduction in any medium or format, as long as you give appropriate credit to the original author(s) and the source, provide a link to the Creative Commons licence, and indicate if changes were made.

The images or other third party material in this article are included in the article's Creative Commons licence, unless indicated otherwise in a credit line to the material. If material is not included in the article's Creative Commons licence and your intended use is not permitted by statutory regulation or exceeds the permitted use, you will need to obtain permission directly from the copyright holder. To view a copy of this licence, visit http:// creativecommons.org/licenses/by/4.0/.

\section{References}

Adriaanse A, Voordijk H, Dewulf G (2010a). Adoption and use of interorganizational ICT in a construction project. Journal of Construction Engineering and Management, 136(9): 1003-1014

Adriaanse A, Voordijk H, Dewulf G (2010b). The use of interorganisational ICT in United States construction projects. Automation in Construction, 19(1): 73-83

Arayici Y, Coates P, Koskela L, Kagioglou M, Usher C, O’Reilly K (2011). Technology adoption in the BIM implementation for lean architectural practice. Automation in Construction, 20(2): 189-195

Arena M, Cross R, Sims J, Uhl-Bien M (2017). How to catalyze innovation in your organization. MIT Sloan Management Review, 58(4): 38-48

Barbosa F, Woetzel J, Mischke J, Ribeirinho M J, Sridhar M, Parsons M, Bertram N, Brown S (2017). Reinventing construction: A route to higher productivity. New York: McKinsey Global Institute

Bew M, Underwood J, Wix J, Storer G (2008). Going BIM in a commercial world. In: Zarli A, Scherer R, eds. eWork and eBusiness in Architecture, Engineering and Construction. Proceedings of the 7th European Conference on Product and Process Modelling. Sophia Antipolis: CRC Press, Taylor and Francis Group, 139-150

Cheung S O, Wong P S, Wu A W (2011). Towards an organizational culture framework in construction. International Journal of Project Management, 29(1): 33-44

Chien K F, Wu Z H, Huang S C (2014). Identifying and assessing critical risk factors for BIM projects: Empirical study. Automation in Construction, 45: 1-15

Cho J, Trent A (2006). Validity in qualitative research revisited. Qualitative Research, 6(3): 319-340

CMMI Product Team (2010). CMMI for development, version 1.3. Technical Report. Software Engineering Institute, Carnegie Mellon University

Cross R, Rebele R, Grant A (2016). Collaborative overload. Harvard Business Review, 94(1): 16

Duncan R B (1972). Characteristics of organizational environments and perceived environmental uncertainty. Administrative Science Quarterly, 17(3): 313-327

Eastman C, Teicholz P, Sacks R, Liston K (2011). BIM Handbook: A Guide to Building Information Modelling for Owners, Managers, Designers, Engineers, and Contractors. 2nd ed. Hoboken: John Wiley \& Sons

Eisenhardt K M (1989). Building theories from case study research. Academy of Management Review, 14(4): 532-550

Gal U, Lyytinen K, Yoo Y (2008). The dynamics of IT boundary objects, information infrastructures, and organisational identities: The introduction of 3D modelling technologies into the architecture, engineering, and construction industry. European Journal of Information Systems, 17(3): 290-304

Gerbert P, Castagnino S, Rothballer C, Renz A, Filitz R (2016). Digital in Engineering and Construction: The Transformative Power of Building Information Modeling. Boston: The Boston Consulting Group Inc.

Gioia D A, Corley K G, Hamilton A L (2013). Seeking qualitative rigor in inductive research: Notes on the Gioia methodology. Organizational Research Methods, 16(1): 15-31

Grilo A, Jardim-Goncalves R (2010). Value proposition on interoperability of BIM and collaborative working environments. Automation in Construction, 19(5): 522-530

Gu N, London K (2010). Understanding and facilitating BIM adoption in the AEC industry. Automation in Construction, 19(8): 988-999

Guth W D, MacMillan I C (1986). Strategy implementation versus middle management self-interest. Strategic Management Journal, 7(4): 313-327

Hall P A (2006). Systematic process analysis: When and how to use it. European Management Review, 3(1): 24-31

Holt D T, Armenakis A A, Feild H S, Harris S G (2007). Readiness for organizational change: The systematic development of a scale. Journal of Applied Behavioral Science, 43(2): 232-255

International Organization for Standardisation (2015). ISO/IEC 33001: 2015 Information technology_Process assessment - Concepts and terminology. Geneva: ISO/IEC

Jones R A, Jimmieson N L, Griffiths A (2005). The impact of organizational culture and reshaping capabilities on change implementation success: The mediating role of readiness for change. 
Journal of Management Studies, 42(2): 361-386

Kamara J M, Augenbroe G, Anumba C J, Carrillo P M (2002). Knowledge management in the architecture, engineering and construction industry. Construction Innovation, 2(1): 53-67

Li H, Lu W, Huang T (2009). Rethinking project management and exploring virtual design and construction as a potential solution. Construction Management and Economics, 27(4): 363-371

Liu S, Xie B, Tivendal L, Liu C (2015). Critical barriers to BIM implementation in the AEC industry. International Journal of Marketing Studies, 7(6): 162-171

Lockamy III A, McCormack K (2004). The development of a supply chain management process maturity model using the concepts of business process orientation. Supply Chain Management, 9(4): 272278

Lu W, Fung A, Peng Y, Liang C, Rowlinson S (2014). Cost-benefit analysis of Building Information Modeling implementation in building projects through demystification of time-effort distribution curves. Building and Environment, 82: 317-327

McGraw Hill Construction (2014). The business value of BIM for construction in major global markets: How contractors around the world are driving innovation with Building Information Modeling. SmartMarket Report. New York: McGraw Hill Construction

Messner J, Kreider R (2013). BIM planning guide for facility owners (version 2.0). Computer Integrated Construction Research Program, Pennsylvania State University

Miettinen R, Paavola S (2014). Beyond the BIM utopia: Approaches to the development and implementation of building information modeling. Automation in Construction, 43: 84-91

Myers M D, Newman M (2007). The qualitative interview in IS research: Examining the craft. Information and Organization, 17(1): 2-26

National Institute of Building Sciences (2015). National BIM Standard-United States Version 3. In: Construction Operation Building Information Exchange (COBie). Washington DC: National Institute of Building Sciences, 1-252

Scandura T A, Williams E A (2000). Research methodology in management: Current practices, trends, and implications for future research. Academy of Management Journal, 43(6): 1248-1264

Siebelink S, Voordijk J T, Adriaanse A M (2018). Developing and testing a tool to evaluate BIM maturity: Sectoral analysis in the Dutch construction industry. Journal of Construction Engineering and Management, 144(8): 05018007

Succar B (2009). Building information modelling framework: A research and delivery foundation for industry stakeholders. Automation in Construction, 18(3): 357-375

Tarakci M, Ateş N Y, Floyd S W, Ahn Y, Wooldridge B (2018). Performance feedback and middle managers' divergent strategic behavior: The roles of social comparisons and organizational identification. Strategic Management Journal, 39(4): 1139-1162

Taylor J E, Levitt R (2007). Innovation alignment and project network dynamics: An integrative model for change. Project Management Journal, 38(3): 22-35

Underwood J, Isikdag U (2009). Handbook of Research on Building Information Modeling and Construction Informatics: Concepts and Technologies. Hershey: IGI Global

Volk R, Stengel J, Schultmann F (2014). Building Information Modeling (BIM) for existing buildings - Literature review and future needs. Automation in Construction, 38: 109-127

Whelan-Berry K S, Gordon J R, Hinings C (2003). Strengthening organizational change processes: Recommendations and implications from a multilevel analysis. Journal of Applied Behavioral Science, 39(2): 186-207

Won J, Lee G, Dossick C, Messner J (2013). Where to focus for successful adoption of building information modeling within organization. Journal of Construction Engineering and Management, 139(11): 04013014

Wooldridge B, Schmid T, Floyd S W (2008). The middle management perspective on strategy process: Contributions, synthesis, and future research. Journal of Management, 34(6): 1190-1221

Yin R K (2003). Case Study Research: Design and Methods. 3rd ed. Thousand Oaks: Sage Publications 